\title{
Ecological Network Analysis of a Virtual Water System in Tibet, China
}

\author{
Junhong Chen ${ }^{1,2}$ and Yadong Mei $^{3, *}$ (D) \\ 1 Guangxi Key Laboratory of Environmental Pollution Control Theory and Technology, \\ Guilin University of Technology, Guilin 541004, China; jhchen@glut.edu.cn \\ 2 Collaborative Innovation Center for Water Pollution Control and Water Safety in Karst Area, \\ Guilin University of Technology, Guilin 541004, China \\ 3 State Key Laboratory of Water Resources and Hydropower Engineering Science, Wuhan University, \\ Wuhan 430072, China \\ * Correspondence: ydmei@whu.edu.cn
}

Citation: Chen, J.; Mei, Y. Ecological Network Analysis of a Virtual Water System in Tibet, China. Water 2021, 13, 3246. https://doi.org/10.3390/ w13223246

Academic Editor: Carmen Teodosiu

Received: 17 October 2021

Accepted: 12 November 2021

Published: 16 November 2021

Publisher's Note: MDPI stays neutral with regard to jurisdictional claims in published maps and institutional affiliations.

Copyright: (c) 2021 by the authors. Licensee MDPI, Basel, Switzerland. This article is an open access article distributed under the terms and conditions of the Creative Commons Attribution (CC BY) license (https:// creativecommons.org/licenses/by/ $4.0 /)$.

\begin{abstract}
With the development of the economy and urbanization, the contradiction between water use and supply is growing, and it is necessary to explore the relationship and evolutionary process of water flow in the water system from a systematic perspective. Although previous studies have analyzed the water system from a holistic point of view, a comprehensive system that considers virtual water flows is currently lacking. The present study establishes a seven-compartment virtual water system in Tibet in 2012 by combining ecological network analysis (ENA) with the input-output model. Socio-economic sectors and virtual water flows are expressed as network compartments and pathways. The information-based ENA is used to evaluate the characteristics of the virtual water system in Tibet, including its robustness and trade-offs between network efficiency and redundancy. Network control analysis is introduced to characterize the control and dependence intensities over the system, while ecological relationships between pairwise compartments are calculated using network utility analysis. The results indicate that Tibet's virtual water system has close to optimal robustness, with higher redundancy and limited efficiency. The agriculture compartment is the main controller, while the energy supply compartment is the most dependent on the virtual water system. The overall systematic relationship that the system has is generally mutualistic and synergistic, the majority of which have a positive relationship, although the control and exploitation relationships are dominant. These results can be used to improve network robustness and are of great significance to the sustainable development of the virtual water system in Tibet.
\end{abstract}

Keywords: virtual water system; ecological network analysis; input-output model; robustness; Tibet

\section{Introduction}

Water is not only a critical resource for human survival, it is also a strategic resource for national development [1]. With the growing population, irrigation, industrialization, and urbanization, urban and rural living standards have continued to improve, and water demand has substantially increased [2,3]. Therefore, it is necessary to develop a sustainable system that is able to solve water-related problems [4]. However, water dissipation, water pollution, and the destruction of the natural water cycle have led to water security concerns, and the uneven distribution of water resources has further led to regional water shortages [5-7]. Globally available water resources account for only 3\% of total water resources, while the annual average consumption is 300-400 times that of coal, oil, and other non-renewable resources [8]. China is among the world's top 13 countries with water shortages, where the water resources that are available per capita are only a quarter of the global average. The western plateau region experiences intense solar radiation, large differences in daily and annual temperatures, high evaporation, and low precipitation, with uneven spatial-temporal distributions. The available water per capita in 
this region is about half the national average. Therefore, the contradiction between water demand and supply is prominent in western China [9].

The social properties of water resources are observed when humans use water for certain activities, while the natural water cycle is linked to the social water cycle $[10,11]$. Water circulation and allocation includes both physical and virtual water embedded in goods and services $[12,13]$. From the perspective of producers, the virtual water content of commodities refers to the amount of water that is actually utilized during production, which is determined by production conditions and water use efficiency. From the perspective of consumers, this quantity is the amount of water needed to produce commodities where they are used [14]. The research of virtual water extends the subject of water into the field of socioeconomics to recognize the driving mechanism of social water cycle and to measure the impacts of human activities on water resource systems [15].

At present, most studies that consider virtual water focus on system simulation, which can be divided into bottom-up and top-down perspectives [16]. The bottom-up approach evaluates the water requirements for all products and services during their production and during trade. Chapagain and Hoekstra [17] calculated the water footprint of tea and coffee in the Netherlands; Chapagain and Orr [18] analyzed the freshwater consumption of tomatoes in Spain. However, the bottom-up approach can only calculate the virtual water trade and consumption of agricultural products, and it is difficult to study the complex calculations of the virtual water trade of animal products and industrial products. In addition, environmental water demand and the dependencies between different economic sectors are often neglected. The top-down approach not only calculates total water consumption during the whole process, but also avoids calculation errors. This approach is usually based on an input-output (I-O) model. It refers to agricultural, industrial, and service products, intuitively reflecting the water exchange between different sectors from a holistic perspective. Guan and Hubacek [9] used the environmental I-O model to calculate crop water consumption in China; Zhao et al. [19] selected the Haihe River Basin as a case study and analyzed virtual water flow directions; and Mubako et al. [20] analyzed virtual water trade in California and Illinois using I-O analysis. Although this method can clearly describe flow directions, it cannot evaluate the indirect water flows between different sectors, which affects analysis of the ecological relationships and the integral throughflows in socio-economic water systems [21].

Ecological network analysis (ENA) is a holistic top-down approach that was initially applied to ecosystems research [22]. It is an effective method to explore the structure and function of complex systems by analyzing the internal structural distribution and ecological relationships [23]. ENA can quantify the impacts of one compartment on the others by evaluating their direct and indirect interactions within the system from a holistic perspective [24]. In dealing with the complexity of the system, ENA can avoid the separate description and evaluation of the internal elements and can put forward information-based indicators that can cover various attributes of the complex system from the systematic aspect [25]. Since Bodini and Bondavalli [26] used this method to consider human settlements, ENA has been applied to the research fields of aquatic ecosystems [27,28], carbon metabolism [29-31], material metabolism [32], sewage treatment [33], electric power systems [34], and water resources systems [11,35-37]. In the system framework, each sector is connected by water flows to build a network and can be expressed as a compartment [38]. Network structure, function, development, and evolution can be studied by matrix algebra [39-41]. Fang and Chen [42] identified the water interdependency among different sectors and the network sustainability in the socio-economic system of the Heihe River Basin using the ENA approach. Li et al. [43] developed a multi-basin water use network to explore the evolution of the Huang, Huai, and Hai River basins and proposed suggestions toward sustainable water use during circumstances in which there is a water shortage. Chen et al. [11] established a water system by considering ecological flow in the Lhasa River Basin based on ENA and assessed system properties and mutual relationships between compartments. Zhang et al. [44] and Zheng et al. [45] analyzed the relationships 
between network indicators and water consumption sectors in the water metabolic systems of Beijing and Chongqing, respectively. In a word, ENA has the advantages of analyzing the complex water flow structures and revealing the hidden relationship among different sectors from a holistic perspective, providing scientific supports for management decisions [46,47]. Previous studies that have focused on identifying the ecological relationship and network structure changes between different nodes from dualistic water cycle, however, have rarely considered the virtual water embedded in products and services and have failed to intuitively reflect the virtual water transfer between socio-economic sectors such as the agriculture, industry, water supply, service, and transportation sectors.

Tibet is the birthplace of many major rivers in Asia as well as an important water tower that maintains the ecosystem and socio-economic development of China as well as Southeast Asia and South Asia [48]. However, there are great differences in the temporal and spatial distribution of water resources in Tibet. The intensive water use areas are mainly distributed in valleys, basins, and hilly areas with low altitude and are suitable for human habitation, which leads to regional water supply and demand contradictions [49]. Since the late 1970s, Tibet has developed from single agro-pastoral economy to a national economic system with the coexistence of industry and the service industry, and its economic ties with other regions have strengthened gradually [50]. When there is economic trade between Tibet and other regions, and the virtual water hidden in products and services also flows among regions. Therefore, the exploration of virtual water transfer is of great significance to the sustainable socio-economic development in Tibet.

The present study selects the Tibet Autonomous Region as a case study and then establishes a virtual water network model to analyze the structure, performance, and function of the system in 2012 by combining the ENA and the I-O model. In detail, the stability of the whole network system is evaluated by information-based ENA indicators, and the virtual water trade as well as pairwise ecological relationships among different socio-economic compartments are also identified by ENA. This paper is organized as follows: after this introduction, Section 2 illustrates the ENA approach and establishes the virtual water network model of Tibet. Section 3 analyzes the results of virtual water transfer and pairwise relationships in the virtual water system, and then the results are compared to related studies. Finally, Section 4 draws a range of conclusions.

\section{Materials and Methods}

\subsection{Study Area}

The Tibet Autonomous Region is located in southwest China and has an area of $1,202,189 \mathrm{~km}^{2}\left(26^{\circ} 50^{\prime}-36^{\circ} 53^{\prime} \mathrm{N}, 78^{\circ} 25^{\prime}-99^{\circ} 06^{\prime} \mathrm{E}\right)$ and accounts for about one eighth of China's total land area (Figure 1). As the roof of the world, Tibet has diverse landform characteristics, including plateaus, mountains, valleys, basins, glaciers, and karst formations. The highest point of Mount Everest is $8848.86 \mathrm{~m}$, and $86 \%$ of the area is at an elevation of more than $4000 \mathrm{~m}$. Influenced by geographical location, atmospheric circulation, and solar radiation, the climate of Tibet has clear regional differences and vertical variability, generally experiencing severe cold in the northwest and moist conditions in the southeast. The annual average temperature in more than $60 \%$ of Tibetan regions is below $0{ }^{\circ} \mathrm{C}$, with a large diurnal temperature difference. The Tibetan Plateau is the most abundant region of solar energy resources in China, with high solar radiation and long sunshine duration. Annual precipitation ranges from $74.8 \mathrm{~mm}$ to $901.5 \mathrm{~mm}$ and decreases from the southeast to the northwest. The rainy season is usually from May to September, which generally accounts for over $90 \%$ of the annual precipitation [49]. There are more than 20 rivers with watershed areas that together comprise an area greater than $10,000 \mathrm{~km}^{2}$, including the Nujiang, Jinsha, Lancang, and Yarlung Tsangpo Rivers. Tibet is in rich in water and hydropower resources. The quantity of surface water accounts for $13.5 \%$ of China's total surface water, and Tibet's regional hydro energy reserves account for about $30 \%$ of China's total hydro energy reserves. 


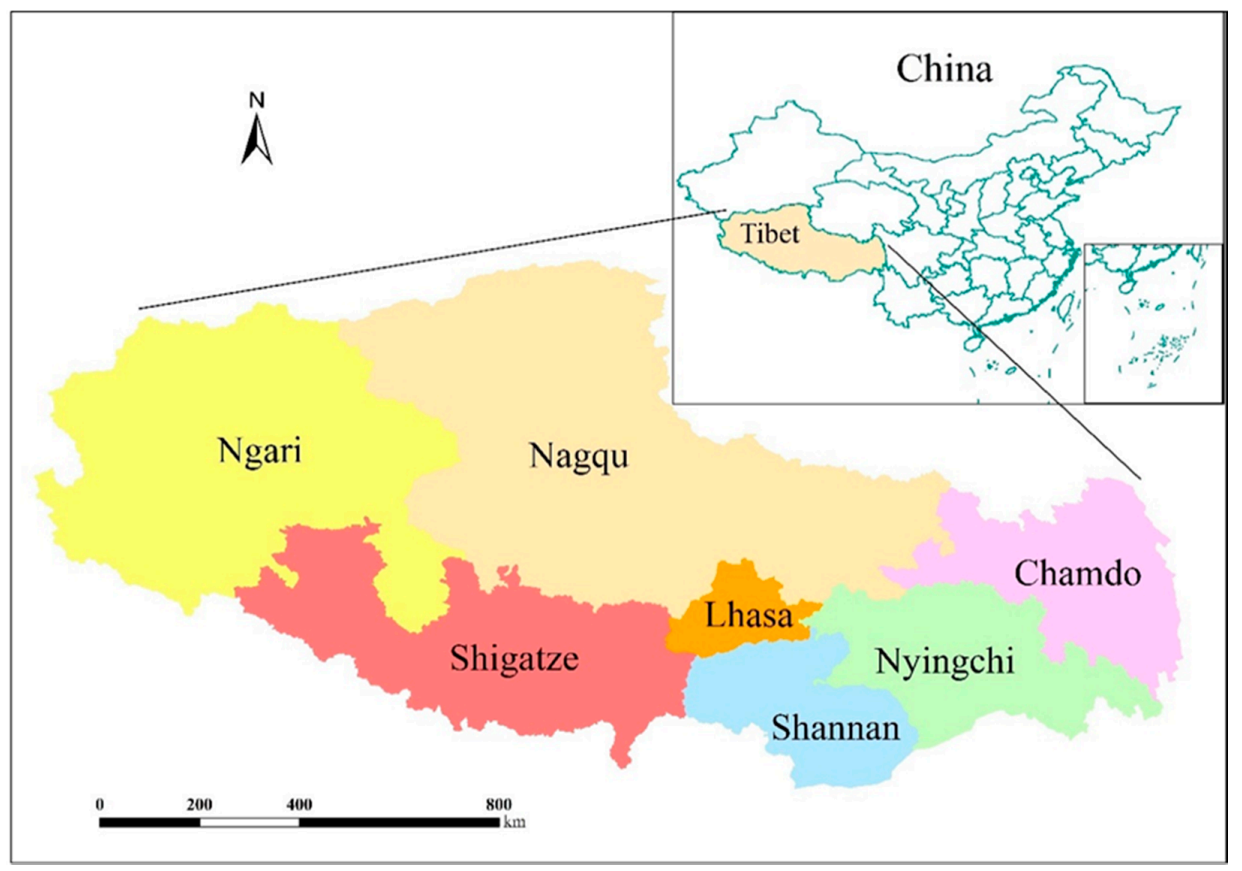

Figure 1. Study area of the Tibet Autonomous Region.

Tibet is one of the five provincial autonomous regions that implements regional ethnic autonomy in China. It is an ethnic autonomous region with Tibetans as the main body. Tibet has a total population of 3.37 million, of which $69 \%$ is located rural in rural areas. In 2017, the gross domestic production was CNY 131 billion. The primary, secondary, and tertiary industry percentages were $9.4 \%, 39.2 \%$, and $51.4 \%$, respectively. Tibet is in a transition period from a traditional agrarian society to a modern industrialized one. With the implementation of the western development strategy, the Tibetan economy has developed rapidly. Industrialization and urbanization have increased water utilization, which is important for the analysis of virtual water trade and pairwise relationships between socio-economic sectors.

\subsection{Data Sources}

This paper uses the I-O table of Tibet in 2012 to calculate the virtual water flows and is divided into 42 sectors. According to the water utilization features and the properties of different sectors, the 42 sectors from the original I-O table are aggregated into 7 sectors (agriculture, mining, manufacturing, energy supply, water supply, construction, and services and transport) [51], which are expressed as network compartments and are shown in Table S1 of the Supplementary Materials in detail. Water use data for the agriculture sector is taken from the agricultural water consumption detailed in the Tibet Water Resources Bulletin 2012 (Department of Water Resources of Tibet Autonomous Region, n.d.). Water use data for the mining, manufacturing, and energy supply sectors are taken from Tibet Statistical Yearbook (Statistical Bureau of Tibet Autonomous Region, n.d.) for the corresponding year. They are the most authoritative data and are approved by the local authorities. In view of the strong positive correlation between water consumption and economic growth, the water consumption data for the water supply, construction, and services and transport sectors are obtained based on the Bulletin of First Water Census of the Tibet Autonomous Region (Ministry of Water Resources of the People's Republic of China, n.d.) from 2011. Taking the economic growth rate in 2012 as the growth rate for water use, the water consumption of these three sectors can be calculated. Since there was little change in the water consumption in 2011 and 2012, there may be some errors in estimating the water consumption of these three sectors in 2012 according to economic growth; however, this will not affect the overall analysis. 


\subsection{Flow Quantification}

As the global trade of goods and services becomes more frequent, the virtual water embodied in the exchange of goods and services forms a water cycle in different sectors and regions. Direct water resources that are consumed by socio-economic sectors can be obtained from the government statistical yearbook, while virtual water cannot be found. Therefore, I-O analysis was used to depict the virtual water flows between different sectors in the socio-economic water system [52]. The purpose of the I-O model of a virtual water system is to evaluate the virtual water flow structure and to show the functional relationship between each compartment. The water resource I-O table is established based on the monetary I-O table, which integrates water consumption and forms a monetarymaterial mixed I-O table to calculate the virtual water for socio-economic sectors in the system $[19,20]$.

In the present study, the virtual water system is disaggregated into seven compartments. The total output can be obtained through the intermediate consumption by the economy and the final demand [53].

$$
T_{i, \text { out }}=\sum_{j=1}^{n} f_{j i}+y_{i}
$$

where $f_{j i}$ indicates the goods flows from compartment $i$ to compartment $j$, and $y_{i}$ represents the final demand of compartment $i$.

Therefore, it is important to convert the monetary I-O table into a physical I-O table. According to the I-O analysis, an appropriate transforming factor enables the conversion from monetary flows to the virtual water flows to become true [54]. The transforming factor reflects the virtual water consumption when the per unit of value products are traded between different compartments, so the amount of virtual water in the system can be calculated:

$$
\mathbf{W}+\varepsilon \mathbf{H}=\varepsilon \mathbf{Q}
$$

where $\mathbf{W}$ is a $7 \times 7$ matrix and refers to the water consumption of each compartment; $\varepsilon$ is a $7 \times 7$ matrix and represents the virtual water intensity matrix, reflecting the amount of virtual water to produce per unit of monetary value; $\mathbf{H}$ is a $7 \times 7$ matrix and represents the monetary flows matrix; and $\mathbf{Q}$ is also a $7 \times 7$ matrix and represents the total output diagonal matrix of each compartment. Then, the virtual water intensity matrix can be calculated as follows [55]:

$$
\varepsilon=\mathbf{W}[\mathbf{Q}-\mathbf{H}]^{-1}
$$

Thus, the present study establishes the virtual water flows matrix for Tibet in 2012. By multiplying the monetary I-O table by the virtual water intensity matrix, the virtual water flows matrix can be obtained [33], which is shown in Table S2:

$$
\mathbf{P}=\varepsilon \mathbf{H}
$$

\subsection{Establishment of Virtual Water Network Model}

To identify the mutual relationships and interdependencies between the compartments as well as the system robustness, a virtual water network model of Tibet was established from the perspective of ENA (Figure 2). The network model was developed based on water imports, exports, intermediate inputs, and consumption, reflecting the water transfer that takes place during production, processing, and trading. In this study, the virtual water network model shares the same boundary with the Tibet Autonomous Region. Necessarily, a steady state was required for each compartment $[38,56]$ :

$$
T_{i, o u t}=\sum_{j=1}^{n} f_{j i}+y_{i}=T_{i, \text { in }}=\sum_{j=1}^{n} f_{i j}+z_{i}
$$


where $n$ represents the number of compartments; $f_{i j}$ Indicates the water flows leaving compartment $j$ to compartment $i ; z_{i}$ and $y_{i}$ are the boundary inputs and boundary outputs of compartment $i$, respectively; and $T_{i, \text { in }}$ and $T_{i, \text { out }}$ represent the total inflows into compartment $i$ and the total outflows of compartment $i$, respectively.

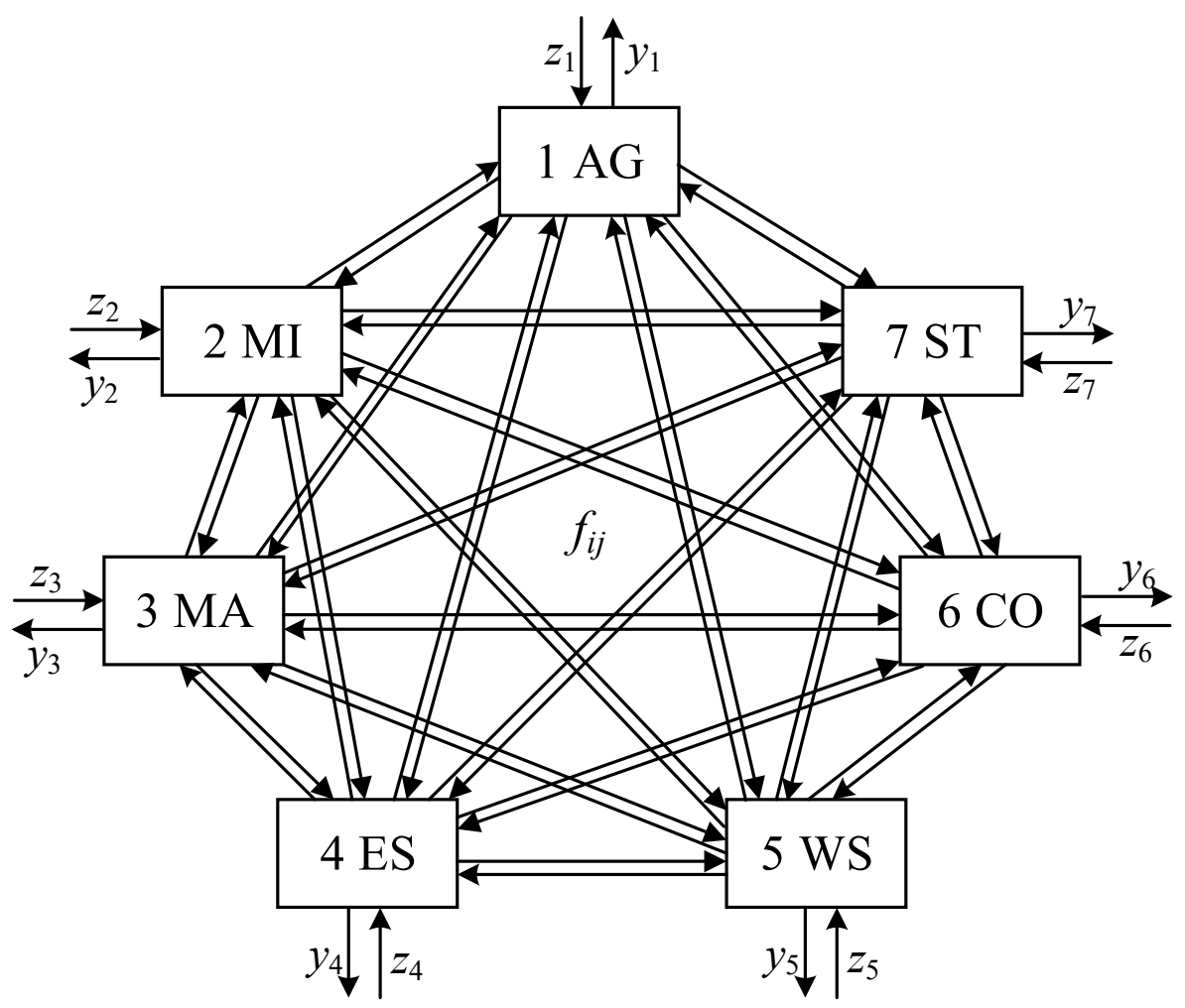

Figure 2. Virtual water network model of Tibet. (Note: AG: agriculture; MI: mining; MA: manufacturing; ES: energy supply; WS: water supply; CO: construction; ST: services and transport).

\subsection{Methodologies}

\subsubsection{Information-Based ENA}

A sustainable system should be capable of conducting sufficient directional power to maintain the integrity and to have a flexible reserve response to external disturbances $[1,24]$. Thus, the system characteristics can be evaluated based on the trade-offs between two equally important but complementary indices: efficiency and redundancy $[12,57,58]$. Efficiency is the level of flow organization while redundancy represents the flexibility or multiplicity of flow pathways between different compartments [24,37]. Fewer pathways can have strong virtual water flows, which result in higher network efficiency. Complex flow pathways have weak virtual water flows, resulting in higher network flexibility. Therefore, the virtual water system requires a high level of robustness to maintain the balance between efficiency and redundancy for long-term sustainable development [15]. The information-based ENA can effectively assess the efficiency, redundancy, and their trade-offs in a system through flow transfer among different compartments [35]. Therefore, the present study introduces the information-based ENA to evaluate the characteristics of the virtual water system in Tibet, including its efficiency, redundancy, and robustness.

MacArthur [59] introduced Shannon's information theory into network flow diversity $(H)$ to indicate the diversity of connections between compartments and decomposed the 
index into two complementary terms: average mutual information $(A M I)$ and conditional entropy $\left(H_{c}\right) . H$ is calculated using Shannon's diversity index:

$$
H=A M I+H_{c}=-k \sum_{i, j} \frac{f_{i j}}{T} \log _{2}\left(\frac{f_{i j}}{T_{i} T_{j}}\right)
$$

where $k$ represents the scale coefficient; $T_{i}$ and $T_{j}$ are the flows into compartment $i$ and out of compartment $j$, respectively. Generally speaking, due to the uneven flow distributions in systems, about $20 \%$ of flows contribute $80 \%$ to $H$ [60].

$A M I$ quantifies the amount of flow diversity encumbered by structural constraints. Thus, it is widely used to estimate the ability of a system to operate in an orderly manner and to maintain network integrity for a long period and represents network efficiency from a structural point of view [61]. There are differences between $H$ and $A M I$ in systems, which are vital for network resilience. $H_{c}$ refers to the amount of residual diversity pertaining to both the inputs and outputs of an average compartment in the network, which evaluates the redundancy from a structural perspective [24]. In general, $A M I$ represents the order and coherent components of a network, while $H_{c}$ represents the disorder, freedom, and the lack of organization of a network. $A M I$ and $H_{c}$ are defined in the following way:

$$
\begin{gathered}
A M I=k \sum_{i, j}\left(f_{i j} / T\right) \log _{2}\left(f_{i j} T / T_{i} T_{j}\right) \\
H_{\mathcal{C}}=-k \sum_{i, j}\left(f_{i j} / T\right) \log _{2}\left(f_{i j}^{2} / T_{i} T_{j}\right)
\end{gathered}
$$

where $T$ refers to the sum of all of the combinations of $f_{i j}$. A higher $A M I$ value indicates that the network structure of the virtual water system is highly organized and that the flows are concentrated with fewer dispersion pathways, corresponding to higher efficiency. On the contrary, a higher $H_{c}$ value indicates that the network structure of the virtual water system is less organized, corresponding to higher redundancy [15]. Appropriate redundancy is important to maintain the stability of the virtual water system and to reduce the risk of collapse when facing internal or external disturbance.

The Finn cycling index (FCI) was proposed by Finn [62] to represent the ratio between recycled flow and the total system throughflow. The cycled flow of compartment $i$ can be calculated as follows:

$$
\operatorname{TSTc}_{i}=\left(n_{i i}-1\right) T_{i} / n_{i i}
$$

Since $\left(n_{i i}-1\right)$ refers to the relative amount of cycled flow, and $n_{i i}$ represents the amount of flow in compartment $i$ generated by a unit of flow starting in compartment $i$ [62]. Then, FCI can be calculated by the total cycling throughflow divided by the total system throughflow:

$$
F C I=\sum T S T c_{i} / T_{i}
$$

$F C I$ quantifies the cycled flow in the system. The value varies from zero to one, with zero indicating no directly or indirectly recycled flow and one indicating all flow is cycled. The increase of $F C I$ is usually interpreted as a response to system pressure [35]. However, the portion of cycled flow can also act as a buffer during disturbances and can help the system to resist external changes.

In general, a network with more diverse pathways will be stagnant but recovers more easily when it encounters external threats. A network with fewer pathways develops more rapidly and is also more fragile. Therefore, efficiency and redundancy are complementary to network stability $[1,63]$. In order to determine the relative relationship between network efficiency and redundancy, an index of the order degree $(\alpha)$ is introduced as:

$$
\alpha=A M I / H
$$


Meanwhile, the quantitative measurement of network robustness $(R)$ is an important feature of system sustainability by concentrating on the roles of both efficiency and redundancy [24]. Intuitively, the optimal robustness of the system depends on network structure, development, and environmental pressure [57]. The relationship between $R$ and ratio $\alpha$ can be calculated as:

$$
R=-\alpha \ln (\alpha)
$$

\subsubsection{Network Control Analysis}

Network control analysis (NCA) focuses on the identification of the impact of each compartment on the network, including the calculation and distribution of direct and indirect throughflow [64] as well as the comparison of dependence and control degrees of each compartment $[12,21]$. Based on the result of the throughflow of each compartment, the dimensionless output-oriented and input-oriented direct flow intensity matrices $\mathbf{G}$ and $\mathrm{G}^{\prime}$ can be calculated as follows:

$$
\begin{gathered}
\mathbf{G}=\left[g_{i j}\right]=\left[f_{i j} / T_{j}\right] \\
\mathbf{G}^{\prime}=\left[g_{i j}^{\prime}\right]=\left[f_{i j} / T_{i}\right]
\end{gathered}
$$

Where $g_{i j}$ and $g_{i j}^{\prime}$ refer to the dimensionless output-oriented and input-oriented direct flow intensities that represent the proportion of the flow from compartment $j$ to compartment $i$ in the total inflow and outflow, respectively.

The dimensionless pairwise integral flow intensity matrices $\mathbf{N}$ and $\mathbf{N}^{\prime}$ synthesize the direct and indirect flow, which can be calculated as follows:

$$
\begin{gathered}
\mathbf{N}=\left[n_{i j}\right]=\sum_{m=0}^{\infty} \mathbf{G}^{m}=\mathbf{G}^{0}+\mathbf{G}^{1}+\mathbf{G}^{2}+\cdots+\mathbf{G}^{m}=(\mathbf{I}-\mathbf{G})^{-1} \\
\mathbf{N}^{\prime}=\left[n_{i j}^{\prime}\right]=\sum_{m=0}^{\infty} \mathbf{G}^{\prime m}=\mathbf{G}^{\prime 0}+\mathbf{G}^{\prime 1}+\mathbf{G}^{\prime 2}+\cdots+\mathbf{G}^{\prime m}=\left(\mathbf{I}-\mathbf{G}^{\prime}\right)^{-1}
\end{gathered}
$$

where $n_{i j}$ and $n_{i j}^{\prime}$ are output-oriented and input-oriented integral flow intensities put forward by Leontief [54]; I refers to the identity matrix; $\mathrm{G}^{0}$ refers to the self-feedback matrix; $\mathbf{G}^{1}$ represents the direct flow matrix; $\mathbf{G}^{m}(m>1)$ represents the indirect flow matrix; and $m$ represents the number of pathways that flow to the target compartment. Therefore, the values of $N$ and $N^{\prime}$ integrate boundary, direct, and indirect flows [65].

The control difference matrix (CD) refers to the absolute control intensity between compartments. The control relationships can be further expressed by the control allocation matrix (CA):

$$
\begin{gathered}
\mathbf{C} \mathbf{D}=\left[c d_{i j}\right]=\left[n_{i j}-n_{j i}^{\prime}\right] \\
\mathbf{C A}=\left[c a_{i j}\right]=\left\{\begin{array}{c}
{\left[\frac{n_{i j}-n_{j i}^{\prime}}{\sum_{i=1}^{m} n_{i j}-n_{j i}^{\prime}}\right],\left(n_{i j}-n_{j i}^{\prime}>0\right)} \\
0,\left(n_{i j}-n_{j i}^{\prime} \leq 0\right)
\end{array}\right.
\end{gathered}
$$

where $c d_{i j}$ denotes control influence between the compartments $j$ and $i . c d_{i j}>0$ represents control intensity, while $c d_{i j} \leq 0$ represents dependent intensity. The value of $c a_{i j}$ ranges from 0 to 1 . If $c a_{i j}$ is closer to 1, then the control relationship is strong and has definite directionality; otherwise, the control relationship is weak and has uncertain directionality. In addition, the mean value $(\mu)$ and standard deviation $(\sigma)$ of positive $c a_{i j}$ are introduced to evaluate the degree of the control relationships in the network.

The control and dependence intensity can be calculated as:

$$
\mathbf{S C}=\left[s c_{j}\right]=\left[\sum_{k=1}^{n} c d_{k j}\right]
$$


where SC refers to the system vector control matrix. If $s c_{j}>0$, compartment $j$ is the dominant over the system; otherwise, it is dependent on the system.

\subsubsection{Network Utility Analysis}

Network utility analysis (NUA) aims at characterizing the ecological relationships between the pairwise compartments within networks. NUA considers the quantified direct and indirect ecological relationships to describe their complexity and the correlations between different compartments in the network [66-68]. Direct relationships between pairwise compartments can be assessed using the net flow utility $d_{i j}$ from the direct utility intensity matrix (D):

$$
\mathbf{D}=\left[d_{i j}\right]=\left[\left(f_{i j}-f_{j i}\right) / T_{i}\right]
$$

Based on the matrix $\mathbf{D}$ defined above, the dimensionless integral utility intensity matrix $(\mathbf{U})$ is put forward [38]. Matrix $\mathbf{U}$ contains the direct, indirect, and integral relationships between different compartments in the system $[42,69]$. The iterative algorithm of matrix $\mathbf{D}$ is used to calculate matrix $\mathbf{U}[39]$ :

$$
\mathbf{U}=\left[u_{i j}\right]=\mathbf{D}^{0}+\mathbf{D}^{1}+\mathbf{D}^{2}+\cdots+\mathbf{D}^{n}=(\mathbf{I}-\mathbf{D})^{-1}
$$

where $\mathbf{D}^{0}$ represents the initial input to each compartment; $\mathbf{D}^{1}$ represents the direct utility relationships; and $\mathbf{D}^{m}(m>1)$ represents the indirect utility relationships between different compartments [70].

The integral interaction between network compartments can be explained by analyzing their direct and indirect relationships. Therefore, sgn $\mathbf{U}$ are further developed as a sign matrix to characterize the ecological relationships between pairwise compartments in the network system [52,71]. There are five possible relationships between pairwise compartments in NUA. If $\operatorname{sgn}\left(u_{i j}, u_{j i}\right)=(+,+)$, then both compartments are in a mutual relationship from which both will benefit. If $\operatorname{sgn}\left(u_{i j}, u_{j i}\right)=(+,-)$, then the compartments are in an exploitation relationship, where the compartment $i$ gains more utility than it transfers to compartment $j$, thus exploiting compartment $j$. On the contrary, if $\operatorname{sgn}\left(u_{i j}, u_{j i}\right)=(-,+)$, then the compartments are in a control relationship, where compartment $i$ loses more utility than it gains from compartment $j$. If $\operatorname{sgn}\left(u_{i j}, u_{j i}\right)=(-,-)$, then both compartments will be damaged in the competition relationship. If $\operatorname{sgn}\left(u_{i j}, u_{j i}\right)=(0,0)$, then the compartments have no effects on each other in a neutral relationship $[11,68]$.

In NUA, the network mutualism index (NM) and the network synergism index (NS) are used to determine the overall systematic relationship between compartments and can be calculated as follows:

$$
\begin{gathered}
N M=\operatorname{sgn} \mathbf{U}(+) / \operatorname{sgn} \mathbf{U}(-) \\
N S=\sum_{j=1}^{n} \sum_{i=1}^{n} u_{i j}
\end{gathered}
$$

where $N M$ represents the ratio of the number of positive signs to the number of negative signs in matrix $\mathbf{U}$ [71]; NS refers to the sum of all of the utility flows in $\mathbf{U}$ [42]. NM and NS can be combined to determine the overall systematic relationship, which tends to be mutualistic or antagonistic [15]. If $N M \geq 1$ and $N S \geq 0$, then the positive relationships are greater than the negative relationships, and the overall systematic relationship is mutualistic; otherwise, the negative relationship is dominant $(N M<1$ or $N S<0)$, and the overall systematic relationship is antagonistic.

\section{Results and Discussion}

\subsection{Stability Analysis of Virtual Water Network}

In the present study, the non-scaled $A M I$ and $H_{c}(k=1)$ denote the authentic efficiency and redundancy of the virtual water system from only the structural perspective, respectively. The value of $A M I$ and $H_{c}$ in the virtual water system of Tibet are 0.630 and 1.962 , respectively. The $A M I$ shows the capacity of the system to operate in an effective 
organization, while $H_{c}$ reflects the capacity of the system to maintain its own stability in case of environmental disturbance [15]. The $A M I$ and $H_{\mathcal{C}}$ in Equations (7) and (8) can be scaled to the network size by replacing $k$ with $T$ and by creating two metrics: ascendency $(A)$ and overhead $(\Phi)$, which represent the efficient and redundant sizes of a network system, respectively [24]. In addition, the values of $A$ and $\Phi$ of the virtual water network were $4.95 \times 10^{9} \mathrm{~m}^{3}$ and $1.54 \times 10^{10} \mathrm{~m}^{3}$, respectively. The calculated result of $F C I$ is 0.149 , indicating that the portion of cycled water is low, the system is characterized by high stability with relatively low efficiency.

The relationship between $\alpha$ and $R$ is shown in Figure 3. An inverted U-shaped curve is drawn based on Equation (12), where $\alpha$ ranges from 0 to 1 . The curve reflects the tradeoffs between network robustness and orderliness. Once $\alpha$ is calculated, then the network robustness as well as the coordination between the network efficiency and redundancy are identified. If $\alpha$ is located to the left side of the inverted U-shaped curve $(\alpha<0.37)$, then the virtual water system is in a stagnant state with excessive redundancy. On the contrary, the virtual water system is developing but fragile if $\alpha$ is located to the right side of the curve $(\alpha>0.37)$ because excessive efficiency may cause the system to be more vulnerable to sudden disturbances [57]. When $\alpha$ is close to 0.37, then the value of $R$ approaches its peak, indicating that the virtual water system attains a high level of robustness by reaching a relative balance between efficiency and redundancy. As shown in Figure $3, \alpha$ is located to the left side of the robustness curve, indicating that the system is relatively redundant, with the calculated $\alpha$ value of 0.243 . The network compartments are closely linked, and there are numerous network pathways, and the flow directions are relatively scattered. Consequently, the value of $R$ is 0.496 for the virtual water system, which is close to the optimal balance, demonstrating that the virtual water system is relatively stable and well organized. Although the high redundancy may play a positive role in maintaining stability, the network structure is not sufficiently organized due to a number of diversified flows in the virtual water system, which limits the efficiency and affects the long-term sustainable development of the system.

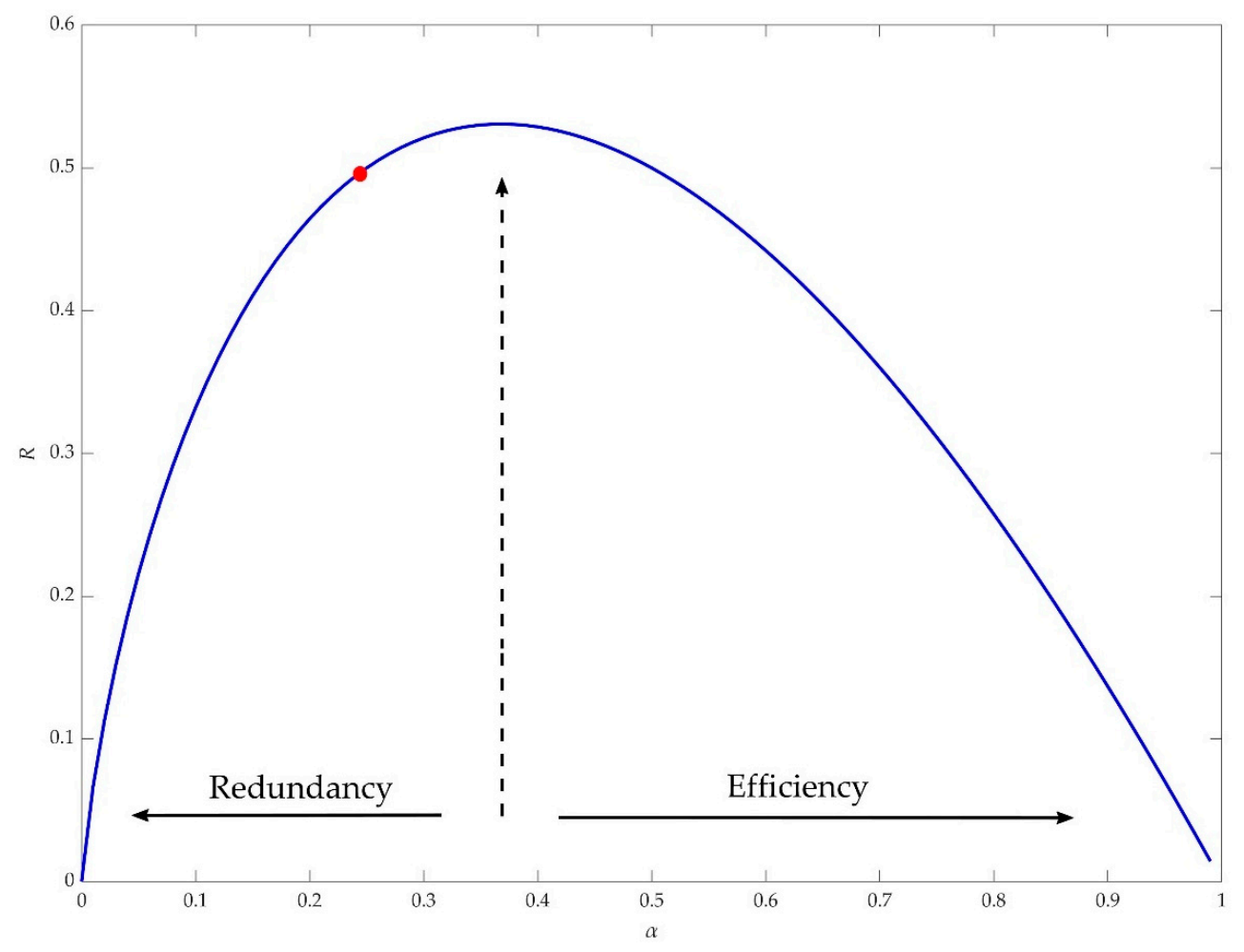

Figure 3. Relationship between the order degree and robustness ${ }^{\circledR}$ in the virtual water system of Tibet. 
The results reveal the overall robustness of the system. Most of the network simulation results show that robustness values usually gather at the top of the inverted U-shaped curve, which indicates that the systems have high stability [60]. One reasonable explanation is that most systems consist of different compartments connected by multiple pathways, some of which are high efficiency, but others are low efficiency or even redundant in representing additional pathways. After a long period of adaptation and evolution, the network flow structure reveals a strong trade-off that could not achieve extremely high efficiency or redundancy. If a system is too efficient, then it will weaken the ability to resist external disturbance and interference. Conversely, if a system is excessively redundant, it will weaken the orderly distribution of virtual water flows, which hinders the internal development of the system [24]. Therefore, the trade-off between network efficiency and redundancy provides scientific support for policy makers to adjust regional industrial structure and to realize regional sustainable development.

\subsection{Network Control Conditions by Network Control Analysis}

The control and dependence intensity values for each compartment of the virtual water system in Tibet are shown in Figure 4. The agriculture compartment is the biggest controller in the network, with an intensity value of 0.98 . The manufacturing and water supply compartments are also important controllers, with values of 0.05 and 0.19 , respectively. Water flows transfer to other compartments, such as mining, energy supply, construction, and services and transport, which are dependent on the network, with respective intensity values of $-0.33,-0.52,-0.12$, and -0.24 . These are the compartments with the highest water consumption. In addition to obtaining water resources from the environment, they also acquire virtual water contained in products and services from other compartments through the network. There are several control-dependence relationships in the virtual water system, the strongest of which are agriculture-mining, agriculture-energy supply, agriculture-construction, and agriculture-services and transport.

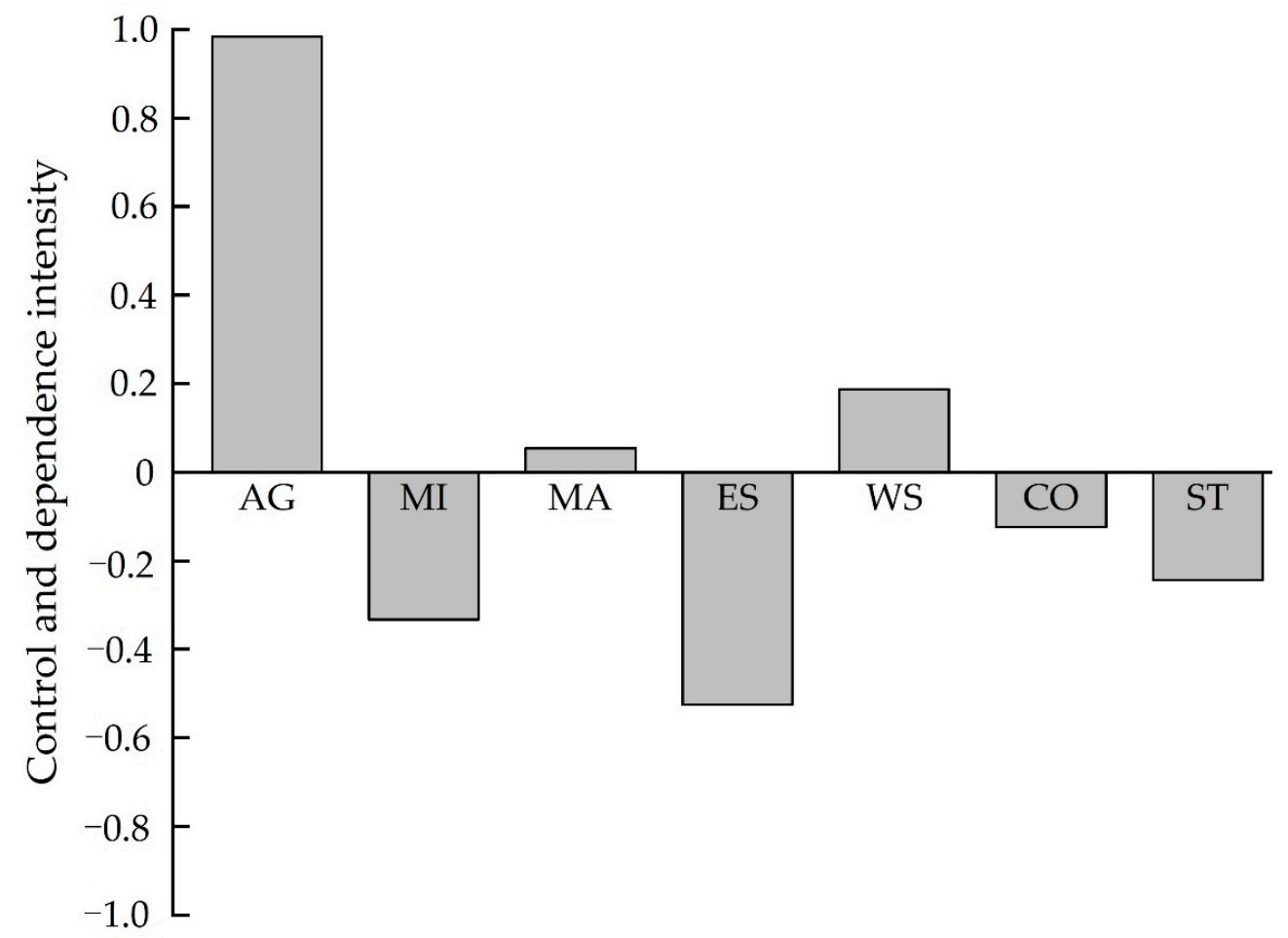

Figure 4. Control and dependence intensity of each compartment in the virtual water system. (Note: AG: agriculture; MI: mining; MA: manufacturing; ES: energy supply; WS: water supply; CO: construction; ST: services and transport). 
Pairwise control relationships for each compartment are shown in Figure 5. Control allocation values greater than 0.8 are considered to be strong relationships, while values less than 0.5 are considered to be weak connections [42]. As shown in Figure 5, the agriculture compartment is the major virtual water resource supplier according to the large number of red squares, and every pairwise control allocation value is greater than 0.9 . Therefore, the agriculture compartment is the biggest dominator in the virtual water system, with a large amount of virtual water transfer to other compartments, especially those with which they have strong relationships. Similarly, water supply and manufacturing compartments are also the dominators that export virtual water to others. Conversely, the mining, manufacturing, and services and transport compartments have numerous dark blue squares, as shown in Figure 5. Therefore, they require a large amount of virtual water supply from other compartments, such as agriculture and water supply.

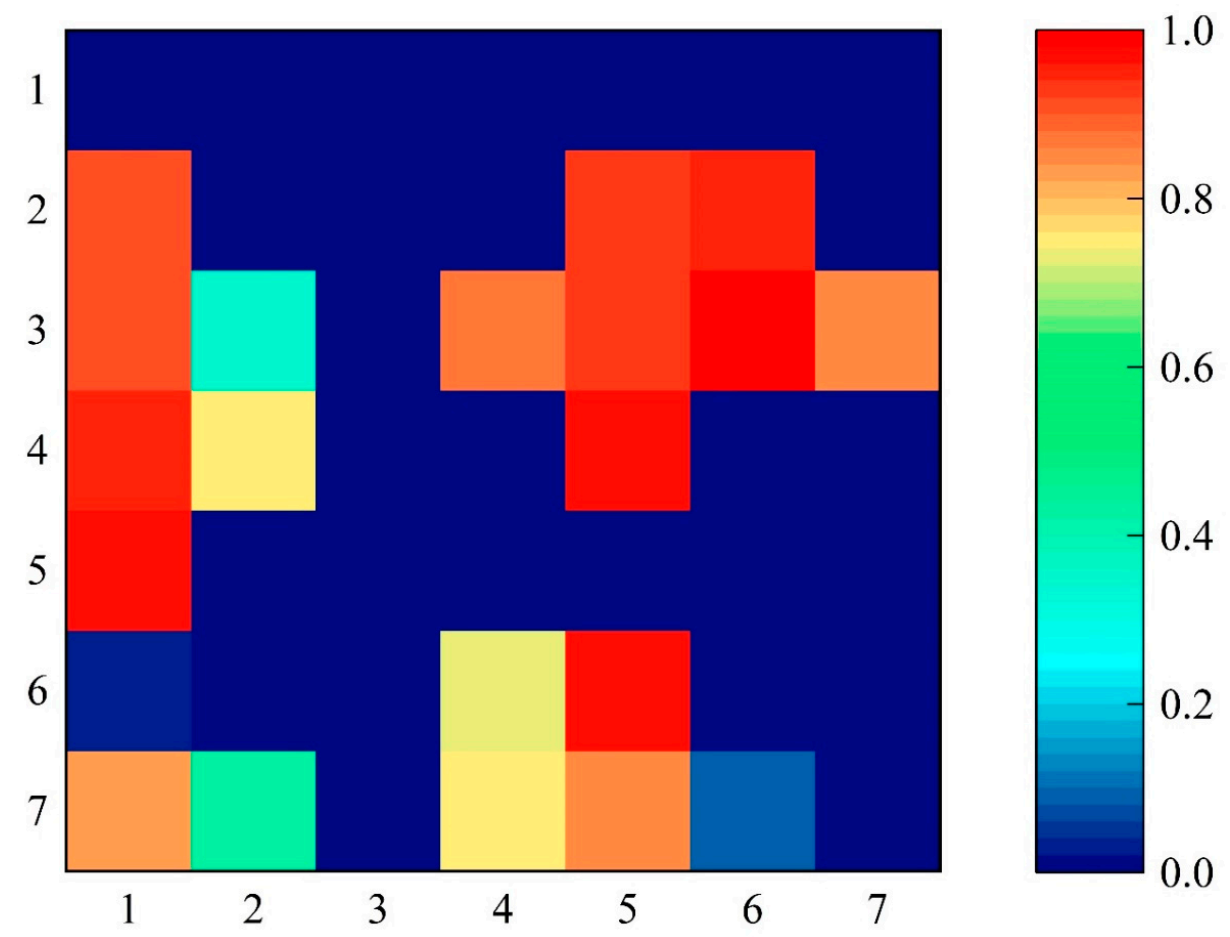

Figure 5. Pairwise control relationships between each compartment in the virtual water system of Tibet. (Note: The control/dependence relationships between each compartment are shown from the matrix column to the matrix row. Compartment number 1: agriculture; 2: mining; 3: manufacturing; 4: energy supply; 5: water supply; 6: construction; 7: services and transport).

At the same time, the strong and weak pathways between each compartment are also evaluated. For instance, mining, energy supply, and services and transport are the compartments that need to obtain a mass of virtual water that is mainly derived from the agriculture and water supply compartments. Therefore, strong pathways exist between the pairwise compartments of agriculture-mining, agriculture-energy supply, agriculture-services and transport, water supply-mining, water supply-energy supply, and water supplyservices and transport. There were also strong linkages between the following pairwise compartments: agriculture-construction, agriculture-manufacturing, agriculture-water supply, manufacturing-mining, energy supply-mining, construction-mining, services and transport-mining, manufacturing-energy supply, water supply-construction, and services and transport-construction. Conversely, compartments such as water supply, construction, and services and transport only obtain a few flows from manufacturing compartment and are greatly dependent on other virtual water suppliers. Therefore, weaker pathways in the system include manufacturing-water supply, manufacturing-construction, manufacturingservices and transport, and energy supply-services and transport. According to the results 
for $\mu$ and $\sigma$, the overall control relationship in the network system is moderately high, with a mean control allocation value $(\mu)$ of 0.763 . On the other hand, the standard deviation for the control allocation $(\sigma)$ is greater, with a value of 0.283 , meaning that the control power needed to be centralized at a higher level.

According to the NCA results, the agriculture compartment is the biggest virtual water supplier, suggesting that most water flows are transferred from agriculture to other compartments. In other words, mining, manufacturing, energy supply, water supply, construction, and services and transport compartments need a large amount of virtual water from the agriculture compartment. For instance, a large amount of straw is needed for the power generation process, and the catering industry also needs a lot of meat from agriculture. Agriculture is the pillar sector in Tibet. It not only the main controller in the network system that develops rapidly and produces considerable benefits to the government, but it is also closely associated with other sectors. Therefore, it can be concluded that agriculture is the primary sector of Tibet and that it plays an important role in economic development. From the sectoral perspective, the controlling effect of agriculture as a main water supplier on mining and construction are obvious, signifying that industrial activities need a virtual water mass from the agricultural products that are associated with a large amount of water consumption. Therefore, it is necessary to improve water use efficiency in agriculture and other industrial sectors to ensure the sustainable development of the virtual water system because agricultural activities directly consume water resources, while other industrial sectors obtain virtual water from agriculture in an indirect way.

\subsection{Ecological Relationships Distribution by Network Utility Analysis}

To solve the complex contradiction between regional water supply and demand, most water resource management policies require reducing physical water use but ignore virtual water resources. Therefore, this study describes the pairwise relationships of virtual water flows among different compartments and reflects the health condition of the virtual water system using NUA. Figure 6 shows 21 integral mutual relationship pairs between compartments after calculating the integral utility intensity matrix $\mathbf{U}$ and sign matrix $\operatorname{sgn}(\mathbf{U})$. The results suggest that there are three kinds of relationships in the virtual water system: exploitation, control, and competition. Exploitation and control are reciprocal relationships that account for more than $85 \%$ of the total. The overall systematic relationship can be determined through the simultaneous analysis of NM and NS. The values of NM and NS calculated by NUA are 1.04 and 17.09, respectively, indicating that the overall systematic relationship of the virtual water system in Tibet is generally mutualistic and synergistic with the positive relationship in the dominant position ( $N M \geq 1$ and $N S \geq 0)$.

Control relationships account for $52 \%$ of the total and are shown in columns 1 and 5 of Figure 6. Mutual relationships in the compartments of agriculture-mining, agriculturemanufacturing, agriculture-energy supply, agriculture-water supply, agriculture-services and transport, water supply-construction, and water supply-services and transport show $(-,+)$ in 2012, which is probably due to the virtual water flow process, i.e., virtual water embedded in agricultural products or services provided by the agriculture compartment are transferred to other compartments via trade pathways. Other control relationships, such as mining-manufacturing, mining-energy supply, and mining-services and transport, exist in the virtual water system and are probably caused by the virtual water embedded in the mineral products that are transferred to other compartments.

Exploitation relationships contribute to $33 \%$ of the total. The compartments of manufacturing-energy supply, manufacturing-water supply, manufacturing-construction, and manufacturing-services and transport show $(+,-)$ in 2012, suggesting that the manufacturing compartment obtained a large amount of water from the energy supply, water supply, construction, and services and transport compartments. Thus, manufacturing is the greatest beneficiary in the virtual water system and has a far-reaching effect on water consumption. Other exploitation relationships, such as mining-water supply, mining- 
construction, and energy supply-water supply also exist in the system, indicating that the water flows from the water supply and construction compartments contribute to the mining and energy supply compartments.

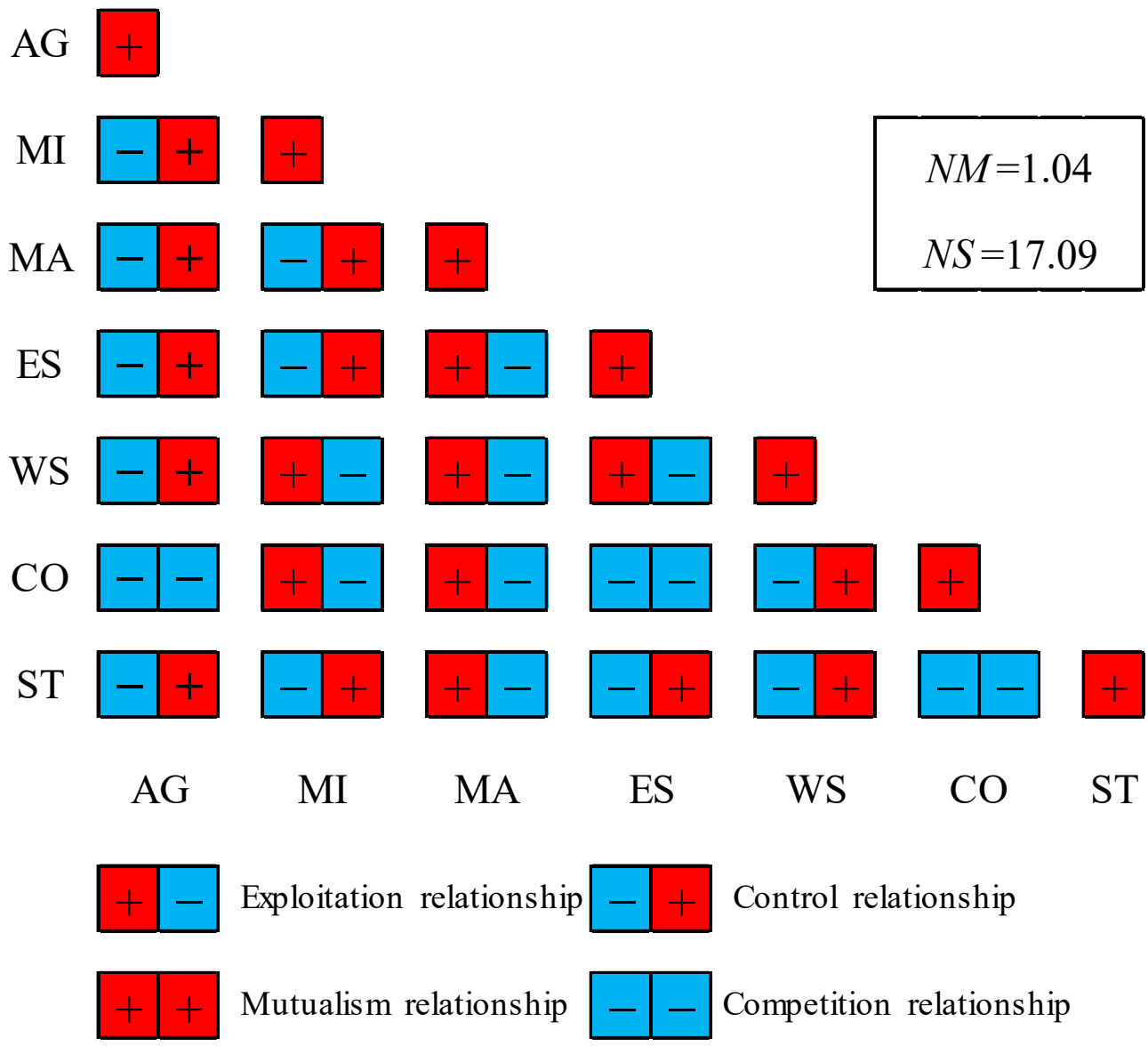

Figure 6. Integral mutual relationships in the virtual water system. (Notes: The integral utility relationships between each compartment are shown from the matrix column to the matrix row).

Competition relationships are the least common and only accounted for $14 \%$ of the total. Mutual relationships in agriculture-construction, energy supply-construction, and energy supply-services and transport compartments show $(-,-)$ in 2012 because they are highly competitive for the limited amount of water and some shared flow pathways. The results illustrate that the agriculture, energy supply, and services and transport compartments extract large amounts of water from the construction compartment, while the construction compartment also needs plenty of water from them. Competition relationships are disadvantageous to the system because they increase water consumption and result in water supply shortages, which lead to negative effects on other compartments and regional sustainable development. Therefore, the water transfer among different compartments can be reduced by improving agricultural machinery technology or by introducing advanced mechanical equipment so as to reduce competition relationships and to prevent the degradation of the virtual water system.

The result of the NUA indicates that unhealthy pairwise relationships of compartments are not conducive to the sustainable development of the virtual water system. First of all, the results show that most water flows are transferred from the agriculture compartment to other compartments. However, it is difficult to dramatically improve the network structure due to the limited irrigation efficiency of agricultural water resources, even if the Tibetan primary industry has achieved a remarkable effect in water saving. Moreover, competitions for low agricultural irrigation efficiency and large water demand for the secondary industry 
are mainly responsible for the negative relationship in the network. On the other hand, some water-saving measures, such as the application of water saving irrigation technology and the use of recycled water, can develop the positive relationship.

\subsection{Comparison with Related Studies}

The continuous improvement and development of ENA have allowed its recent application in different areas. The results from this study are compared with those from Ganzhou District [72] and the Baiyangdian Basin [73], as shown in Table 1. The socioeconomic water system in the Ganzhou District considers virtual water flows, while the water use system in the Baiyangdian Basin considers physical water flows. Therefore, the comparison is meaningful for revealing the characteristics, structure, relationship, and sustainability of different systems. The six compartments in the Ganzhou District are farming, livestock, fishing, industry, construction, and services. The five compartments in the Baiyangdian Basin are aquatic systems, primary industry, secondary industry, tertiary industry, and resident consumption, which are different from the present study. The Ganzhou socio-economic water system was established using network environ analysis, a branch of ENA that reveals the flow distributions and analyzes the current state of the network using three ecosystem-based indicators: average path length, cycling index, and the indirect-to-direct ratio. A water use system model is constructed using ENA to evaluate the functioning of the Baiyangdian Basin in a holistic framework. Indicators such as total system throughput, average mutual information, development capacity, and ascendency are used to evaluate the properties of the water use system. In this study, an I-O model is applied to quantify virtual water flow; the information-based ENA reveals the network characteristics and the balance between network efficiency and redundancy using a single indicator, i.e., robustness; the control and dependence intensities over the system are identified by NCA; and the ecological relationships between pairwise compartments are identified from a holistic view by NUA.

Table 1. Comparison of related studies.

\begin{tabular}{|c|c|c|c|}
\hline & Fang et al. & Mao et al. & This Paper \\
\hline Location & Ganzhou District & Baiyangdian Basin & Tibet Autonomous Region \\
\hline Method & Network environ analysis & Ecological network analysis & $\begin{array}{l}\text { Ecological network analysis } \\
\text { coupling with the I-O model }\end{array}$ \\
\hline Results & $\begin{array}{l}\text { Network structure influenced } \\
\text { flow circulation. The network is } \\
\text { dependent on large boundary } \\
\text { water input. Three indices, the } \\
\text { cycling index, indirect-to-direct } \\
\text { ratio, and average path length } \\
\text { show that water consumption } \\
\text { efficiency is lower than the } \\
\text { natural system. }\end{array}$ & $\begin{array}{l}\text { The water use system encounters } \\
\text { a lasting degradation in system } \\
\text { organization with } A M I \text { decreases } \\
\text { in an annual rate of } 0.6 \% \text {, while } \\
\text { annual growth rate of ascendency } \\
\text { and total system throughput are } \\
10.1 \% \text { and } 11.3 \% \text {, respectively. }\end{array}$ & $\begin{array}{l}\text { The network is more efficient with } \\
\text { less redundancy. Agriculture is } \\
\text { the largest controller while energy } \\
\text { supply is the largest dependent. } \\
\text { The network is mutualistic and } \\
\text { synergistic overall although } \\
\text { exploitation and control } \\
\text { relationships are dominant. }\end{array}$ \\
\hline
\end{tabular}

In the Ganzhou District, structural analysis demonstrates the network structure change during the study period, which concentrates on three agricultural compartments (farming, livestock, and fishing). The network system maintains a large amount of water inputs, which accounts for more than $80 \%$ of the integral flows. Water use efficiency decreases during the study period and is lower than natural systems. Fang et al. [72] describes the temporal change in network efficiency, which could not be evaluated in Tibet due to the lack of statistical data over multiple years. The results manifest that the ENA method can holistically evaluate the system attributes and fluctuation of the water use system in the Baiyangdian Basin. Mao et al. [73] calculates that the annual growth rate of system ascendency, and the total system throughput reached $10.1 \%$ and $11.3 \%$, respectively, while the $A M I$ index decreases in an annual rate of $0.6 \%$, indicating that the water use system 
encounters a lasting degradation in system organization and development degree though with ascending system activities in the study area. In this study, the agriculture compartment has the greatest water consumption, similar to the socio-economic water system in Ganzhou District. The information-based ENA implies that the virtual water system in Tibet has a high stability due to the close connection between network compartments with numerous pathways and flow directions, which is similar to the results in the Ganzhou District and Baiyangdian Basin. Reducing pathways and increasing interflows among compartments can help to improve network efficiency. Furthermore, the internal network structure is evaluated by NCA and NUA based on the flow distributions between the compartments and pathways in the network system, which is not considered by Fang et al. [72] and Mao et al. [73]. The agriculture and water supply compartments are the two largest controllers, while the energy supply, mining, and services and transport compartments are the three largest dependents in Tibet's virtual water system. The NUA results indicate that the network system is mutualistic and synergistic overall. There is less competition, while control and exploitation relationships are dominant. NUA and NUA results reveal integral mutual relationships between pairwise compartments, highlighting the controllers and dependents, as well as the beneficiaries and victims in the network, which is helpful for optimizing socio-economic structure to increase water use efficiency.

\section{Conclusions}

The present study calculates the virtual water flows for Tibet in 2012 using an I-O model and establishes a seven-compartment virtual water network model based on the ENA method. Through the analysis of the network structure, relationships, and characteristics, the sustainability of the virtual water system in Tibet can be evaluated and analyzed. Information-based ENA can reflect the trade-off between network efficiency and redundancy. The results reveal that the virtual water system is relatively stable and has higher redundancy and limited efficiency. NCA reveals the control and dependence intensities of network compartments, and the results show that the agriculture compartment is the main controller, while the energy supply compartment is the most dependent on the virtual water system. NUA shows the index values of NM and NS are 1.04 and 17.09, respectively, indicating that the overall systematic relationship of the virtual water system is generally mutualistic and synergistic with the positive relationship in dominant position. Exploitation, control, and competition are three kinds of relationships in the virtual water system. Control and exploitation relationships are dominant and account for more than $85 \%$ of the total, while the competition relationship is the least common relationships in the virtual water system.

This study considers virtual water flows in the virtual water system and establishes a network model combining the I-O model with the ENA method. The results contribute to a deeper understanding of network robustness and the pairwise relationships between different compartments. It also provides scientific support for depicting the virtual water flow in the system and adjusting regional industrial structure. However, limited by the lack of statistical data over multiple years, this study only analyzes the structure, characteristics, and performance of Tibet's virtual water system in 2012 and could not evaluate the complexity and temporal variability of the system. There is still no standard criterion for the system robustness interval. Moreover, the method can be widely applied to regional, national, and global scales. In the future research works, more regions could be explored to reflect the stability of the system as well as the relationships between the pairwise sectors. In addition, the spatial and temporal changes in the network relationships can be evaluated to further understand the virtual water system.

Supplementary Materials: The following are available online at https: / www.mdpi.com/article/ 10.3390/w13223246/s1, Table S1: Aggregation of sectors in the input-output table, Table S2: The virtual water flows matrix of Tibet in 2012. 
Author Contributions: Conceptualization, J.C. and Y.M.; methodology, J.C.; validation, Y.M.; formal analysis, J.C.; investigation, J.C. and Y.M.; resources, J.C. and Y.M.; writing-original draft preparation, J.C.; writing-review and editing, J.C. and Y.M.; project administration, Y.M.; funding acquisition, J.C. All authors have read and agreed to the published version of the manuscript.

Funding: This research was supported by the National Natural Science Foundation of China (42101270; 91647204) and the Foundation of Guilin University of Technology (GUTQDJJ2020083).

Institutional Review Board Statement: Not applicable.

Informed Consent Statement: Not applicable.

Data Availability Statement: The data presented in this study are available on request from the corresponding author. The data are not publicly available due to privacy.

Acknowledgments: Special thanks to Yue Ben, Yueyun Chen, Zhenhui Wu, and Di Zhu for providing instructions and suggestions on this work.

Conflicts of Interest: The authors declare no conflict of interest.

\section{References}

1. Li, Y.; Yang, Z.F. Quantifying the sustainability of water use systems: Calculating the balance between network efficiency and resilience. Ecol. Model. 2011, 222, 1771-1780. [CrossRef]

2. Wu, F.; Zhuang, Z.; Liu, H.L.; Shiac, Y.C. Evaluation of Water Resources Carrying Capacity Using Principal Component Analysis: An Empirical Study in Huai'an, Jiangsu, China. Water 2021, 13, 2587. [CrossRef]

3. Bernabé-Crespo, M.B.; Peña-Ramos, J.A. The Management of Water Resources in a Disputed Border: The Case of Gazivoda Reservoir (Kosovo). Front. J. Soc. Technol. Environ. Sci. 2019, 8, 319-340. [CrossRef]

4. Shafique, M.; Kim, R. Recent Progress in Low-Impact Development in South Korea: Water Management Policies, Challenges and Opportunities. Water 2018, 10, 435. [CrossRef]

5. Peña-Ramos, J.A.; Bagus, P.; Fursova, D. Water conflicts in central Asia: Some recommendations on the non-conflictual use of water. Sustainability 2021, 13, 3479. [CrossRef]

6. Peña-Ramos, J.A.; Luis, F.R.R. Past, Present, and Future Conflicts over Freshwater. Int. J. Environ. Sustain. 2021, 17, 19-31. [CrossRef]

7. Chen, W.; Wu, S.; Lei, Y.; Li, S. Virtual water export and import in China's foreign trade: A quantification using input-output tables of China from 2000 to 2012. Resour. Conserv. Recycl. 2018, 132, 278-290. [CrossRef]

8. Feng, K.; Hubacek, K.; Pfisher, S.; Yu, Y.; Sun, L. Virtual scarce water in China. Environ. Sci. Technol. 2014, 48, 7704-7713. [CrossRef]

9. Guan, D.; Hubacek, K. Assessment of regional trade and virtual water flows in China. Ecol. Econ. 2007, 61, 159-170. [CrossRef]

10. Lu, S.; Zhang, X.; Bao, H.; Skitmore, M. Review of social water cycle research in a changing environment. Renew. Sust. Energy Rev. 2016, 63, 132-140. [CrossRef]

11. Chen, J.; Mei, Y.; Xiao, W. Establishment of the ecological relationships and properties of the Lhasa River Basin water resources system, China. Sustain. Cities Soc. 2019, 47, 101477. [CrossRef]

12. Yang, Z.; Mao, X.; Zhao, X.; Chen, B. Ecological network analysis on global virtual water trade. Environ. Sci. Technol. 2012, 46, 1796-1803. [CrossRef]

13. He, C.; Huang, G.; Liu, L.; Xu, X.; Li, Y. Evolution of virtual water metabolic network in developing regions: A case study of Guangdong province. Ecol. Indicat. 2020, 108, 105750. [CrossRef]

14. Allen, J.A. Virtual water: A strategic resource global solutions to regional deficits. Groundwater 1998, 36, 545-546. [CrossRef]

15. Cui, D.; Zeng, W.; Ma, B.; Zhuo, Y.; Xie, Y. Ecological network analysis of an urban water metabolic system: Integrated metabolic processes of physical and virtual water. Sci. Total Environ. 2021, 787, 147432. [CrossRef] [PubMed]

16. Xu, W.; Xie, Y.; Cai, Y.; Li, L.; Wang, B.; Yang, Z. Environmentally-extended input-output and ecological network analysis for Energy-Water- $\mathrm{CO}_{2}$ metabolic system in China. Sci. Total Environ. 2021, 758, 143931. [CrossRef]

17. Chapagain, A.K.; Hoekstra, A.Y. The water footprint of coffee and tea consumption in the Netherlands. Ecol. Econ. 2007, 64, 109-118. [CrossRef]

18. Chapagain, A.K.; Orr, S. An improved water footprint methodology linking global consumption to local water resources: A case of Spanish tomatoes. J. Environ. Manag. 2009, 90, 1219-1228. [CrossRef]

19. Zhao, X.; Yang, H.; Yang, Z.; Chen, B.; Yan, Q. Applying the input-output method to account for water footprint and virtual water trade in the Haihe River Basin in China. Environ. Sci. Technol. 2010, 44, 9150-9156. [CrossRef]

20. Mubako, S.; Lahiri, S.; Lant, C. Input-output analysis of virtual water transfers: Case study of California and Illinois. Ecol. Econ. 2013, 93, 230-238. [CrossRef]

21. Mao, X.; Yang, Z. Ecological network analysis for virtual water trade system: A case study for the Baiyangdian Basin in Northern China. Ecol. Inform. 2012, 10, 17-24. [CrossRef]

22. Hannon, B. The structure of ecosystems. J. Theor. Biol. 1973, 41, 535-546. [CrossRef] 
23. Patten, B.C.; Bosserman, R.W.; Finn, J.T.; Cale, W.G. Propagation of Cause in Ecosystems. In Systems Analysis and Simulation in Ecology; Patten, B.C., Ed.; Academic Press: New York, NY, USA, 1976; pp. 457-579. ISBN 978-0-12-547204-3.

24. Ulanowicz, R.E.; Goerner, S.J.; Lietaer, B.; Gomez, R. Quantifying sustainability: Resilience, efficiency and the return of information theory. Ecol. Complex. 2009, 6, 27-36. [CrossRef]

25. Yang, Z.; Mao, X. Wetland system network analysis for environmental flow allocations in the Baiyangdian Basin, China. Ecol. Model. 2011, 222, 3785-3794. [CrossRef]

26. Bodini, A.; Bondavalli, C. Towards a sustainable use of water resources: A whole-ecosystem approach using network analysis. Int. J. Environ. Pollut. 2002, 18, 463-485. [CrossRef]

27. Mao, X.; Yang, Z. Functional assessment of interconnected aquatic ecosystems in the Baiyangdian Basin-An ecological-networkanalysis based approach. Ecol. Model. 2011, 222, 3811-3820. [CrossRef]

28. Zeng, Y.; Zhao, Y.; Qi, Z. Evaluating the ecological state of Chinese Lake Baiyangdian (BYD) based on Ecological Network Analysis. Ecol. Indicat. 2021, 127, 107788. [CrossRef]

29. Lu, Y.; Chen, B.; Feng, K.; Hubacek, K. Ecological network analysis for carbon metabolism of eco-industrial parks: A case study of a typical eco-industrial park in Beijing. Environ. Sci. Technol. 2015, 49, 7254-7264. [CrossRef]

30. Fang, D.; Chen, B. Information-based ecological network analysis for carbon emissions. Appl. Energy 2019, 238, 45-53. [CrossRef]

31. Guan, Y.; Bai, J.; Tian, X.; Zhi, L.; Yu, Z. Integrating ecological and socio-economic systems by carbon metabolism in a typical wetland city of China. J. Clean. Prod. 2021, 279, 123342. [CrossRef]

32. Wang, X.; Zhang, Y.; Yu, X. Characteristics of Tianjin's material metabolism from the perspective of ecological network analysis. J. Clean. Prod. 2019, 239, 118115. [CrossRef]

33. Zheng, B.; Huang, G.; Liu, L.; Zhai, M.; Guan, Y. Metabolism of urban wastewater: Ecological network analysis for Guangdong Province, China. J. Clean. Prod. 2019, 217, 510-519. [CrossRef]

34. Guo, R.; Zhu, X.; Chen, B.; Yue, Y. Ecological network analysis of the virtual water network within China's electric power system during 2007-2012. Appl. Energ. 2016, 168, 110-121. [CrossRef]

35. Pizzol, M.; Scotti, M.; Thomsen, M. Network Analysis as a tool for assessing environmental sustainability: Applying the ecosystem perspective to a Danish Water Management System. J. Environ. Manag. 2013, 118, 21-31. [CrossRef]

36. Hai, R.; Shi, H.; Zhang, B.; Zhai, Y.; Li, Y.; Wang, W. An ecological information analysis-based approach for assessing the sustainability of water use systems: A case study of the Huaihe River Basin, China. Clean Technol. Environ. Policy 2015, 17, 2197-2211. [CrossRef]

37. Kharrazi, A.; Akiyama, T.; Yu, Y.; Li, J. Evaluating the evolution of the Heihe River basin using the ecological network analysis: Efficiency, resilience, and implications for water resource management policy. Sci. Total Environ. 2016, 576, 688-696. [CrossRef] [PubMed]

38. Bodini, A. Building a systemic environmental monitoring and indicators for sustainability: What has the ecological network approach to offer? Ecol. Indicat. 2012, 15, 140-148. [CrossRef]

39. Fath, B.D.; Patten, B.C. Review of the foundations of network environ analysis. Ecosystems 1999, 2, 167-179. [CrossRef]

40. Ulanowicz, R.E. Quantitative methods for ecological network analysis. Comp. Biol. Chem. 2004, 28, 321-339. [CrossRef]

41. Liu, G.; Yang, Z.; Chen, B.; Zhang, L.; Zhang, Y.; Su, M. An ecological network perspective in improving reserve design and connectivity: A case study of Wuyishan nature reserve in China. Ecol. Model. 2015, 306, 185-194. [CrossRef]

42. Fang, D.; Chen, B. Ecological network analysis for a virtual water network. Environ. Sci. Technol. 2015, 49, 6722-6730. [CrossRef]

43. Li, Y.; Wang, Y.; Gao, X.; Hao, T.; Liu, E.; Wang, X. Multi-basin water use network model for evaluating evolution of water resource systems toward sustainable water use. J. Clean. Prod. 2021, 281, 124855. [CrossRef]

44. Zhang, Y.; Yang, Z.; Fath, B.D. Ecological network analysis of an urban water metabolic system: Model development, and a case study for Beijing. Sci. Total Environ. 2010,408, 4702-4711. [CrossRef]

45. Zheng, X.; Huang, G.; Liu, L.; Zheng, B.; Zhang, X. A multi-source virtual water metabolism model for urban systems. J. Clean. Prod. 2020, 275, 124107. [CrossRef]

46. Wu, X.J.; Li, Y.P.; Liu, J.; Huang, G.H.; Ding, Y.K.; Sun, J.; Zhang, H. Identifying optimal virtual water management strategy for Kazakhstan: A factorial ecologically-extended input-output model. J. Environ. Manag. 2021, 297, 113303. [CrossRef]

47. Vega, C.D.L.; Schückel, U.; Horn, S.; Kröncke, I.; Asmus, R.; Asmus, H. How to include ecological network analysis results in management? A case study of three tidal basins of the Wadden Sea, south-eastern North Sea. Ocean. Coast. Manag. 2018, 163, 401-416. [CrossRef]

48. Immerzeel, W.; Stoorvogel, J.; Antle, J. Can payments for ecosystem services secure the water tower of Tibet. Agric. Syst. 2008, 96, 52-63. [CrossRef]

49. Wu, Z.; Mei, Y.; Chen, J.; Hu, T.; Xiao, W. Attribution Analysis of Dry Season Runoff in the Lhasa River Using an Extended Hydrological Sensitivity Method and a Hydrological Model. Water 2019, 11, 1187. [CrossRef]

50. Xie, W.; Hu, S.; Li, F.; Cao, X.; Tang, Z. Carbon and Water Footprints of Tibet: Spatial Pattern and Trend Analysis. Sustainability 2020, 12, 3294. [CrossRef]

51. Cao, T.; Wang, S.; Chen, B. Virtual water analysis for the Jing-Jin-Ji region based on multiregional input-output model. Acta Ecol. Sin. 2018, 38, 788-799. (In Chinese)

52. Zhang, G.; Huang, G.; Liu, L.; Niu, G.; Li, J.; McBean, E. Ecological network analysis of an urban water metabolic system based on input-output model: A case study of Guangdong, China. Sci. Total Environ. 2019, 670, 369-378. [CrossRef] [PubMed] 
53. Zhang, Y.; Zheng, H.; Fath, B.D.; Liu, H.; Yang, Z.; Liu, G.; Su, M. Ecological network analysis of an urban metabolic system based on input-output tables: Model development and case study for Beijing. Sci. Total Environ. 2014, 468-469, 642-653. [CrossRef]

54. Leontief, W. Environmental repercussions and the economic structure: An input-output approach. Rev. Econ. Stat. 1970, 52, 262-271. [CrossRef]

55. Rhee, H.C.; Chung, H.S. Change in $\mathrm{CO}_{2}$ emission and its transmissions between Korea and Japan using international input-output analysis. Ecol. Econ. 2006, 58, 788-800. [CrossRef]

56. Matamba, L.; Kazanci, C.; Schramski, J.R.; Blessing, M.; Alexander, P.; Patten, B.C. Throughflow analysis: A stochastic approach. Ecol. Model. 2009, 220, 3174-3181. [CrossRef]

57. Kharrazi, A.; Rovenskaya, E.; Fath, B.D.; Yarime, M.; Kraines, S. Quantifying the sustainability of economic resource networks: An ecological information-based approach. Ecol. Econ. 2013, 90, 177-186. [CrossRef]

58. Kharrazi, A.; Fath, B.D.; Katzmair, H. Advancing Empirical Approaches to the Concept of Resilience: A Critical Examination of Panarchy, Ecological Information, and Statistical Evidence. Sustainability 2016, 8, 935. [CrossRef]

59. MacArthur, R. Fluctuations of animal populations and a measure of community stability. Ecology 1955, 36, 533-536. [CrossRef]

60. Fath, B.D.; Asmus, H.; Asmus, R.; Baird, D.; Borrett, S.R.; de Jonge, V.N.; Ludovisi, N.; Niquil, N.; Scharler, U.M.; Schückel, U.; et al. Ecological network analysis metrics: The need for an entire ecosystem approach in management and policy. Ocean. Coast. Manag. 2019, 174, 1-14. [CrossRef]

61. Li, A.; Zheng, H. Energy security and sustainable design of urban systems based on ecological network analysis. Ecol. Indicat. 2021, 129, 107903. [CrossRef]

62. Finn, J.T. Flow analysis of models of the Hubbard Brook ecosystem. Ecology 1980, 61, 562-571. [CrossRef]

63. Safi, G.; Giebels, D.; Arroyo, N.L.; Heymans, J.J.; Preciado, I.; Raoux, A.; Schückel, U.; Tecchio, S.; de Jonge, V.N.; Niquil, N. Vitamine ENA: A framework for the development of ecosystem-based indicators for decision makers. Ocean. Coast. Manag. 2019, 174, 116-130. [CrossRef]

64. Muhtar, P.; Xia, J.; Muyibul, Z.; Zihriya, B.; Abliz, A.; Zhang, M. Evaluating the evolution of oasis water metabolism using ecological network analysis: A synthesis of structural and functional properties. J. Clean. Prod. 2021, 280, 124422. [CrossRef]

65. Patten, B.C. Network perspectives on ecological indicators and actuators: Enfolding, observability, and controllability. Ecol. Indicat. 2006, 6, 6-23. [CrossRef]

66. Fath, B.D. Community-level relations and network mutualism. Ecol. Model. 2007, 208, 56-67. [CrossRef]

67. Liu, G.Y.; Yang, Z.F.; Chen, B.; Zhang, Y. Ecological network determination of sectoral linkages, utility relations and structural characteristics on urban ecological economic system. Ecol. Model. 2011, 222, 2825-2834. [CrossRef]

68. Li, S.; Zhang, Y.; Yang, Z.; Liu, H.; Zhang, J. Ecological relationship analysis of the urban metabolic system of Beijing, China. Environ. Pollut. 2012, 170, 169-176. [CrossRef] [PubMed]

69. Xia, L.; Zhang, Y.; Wu, Q.; Liu, L. Analysis of the ecological relationships of urban carbon metabolism based on the eight nodes spatial network model. J. Clean. Prod. 2017, 140, 1644-1651. [CrossRef]

70. Yang, J.; Chen, B. Energy-water nexus of wind power generation systems. Appl. Energy 2016, 169, 1-13. [CrossRef]

71. Lobanova, G.; Fath, B.D.; Rovenskaya, E. Exploring simple structural configurations for optimal network mutualism. Commun. Nonlinear Sci. 2009, 14, 1461-1485. [CrossRef]

72. Fang, D.; Fath, B.D.; Chen, B.; Scharler, U.M. Network environ analysis for socio-economic water system. Ecol. Indicat. 2014, 47, 80-88. [CrossRef]

73. Mao, X.; Yuan, D.; Wei, X.; Chen, Q.; Yan, C.; He, L. Network Analysis for a Better Water Use Configuration in the Baiyangdian Basin, China. Sustainability 2015, 7, 1730-1741. [CrossRef] 